\title{
Critical Biot Number of a Periodic Array of Rectangular Fins
}

Marios M. Fyrillas, Theodoros Leontiou

- School of Engineering

\begin{abstract}
We consider the heat transfer problem associated with a periodic array of rectangular fins subjected to convection heat transfer with a uniform heat transfer coefficient. Our analysis differs from the classical approach as (i) we consider two-dimensional (2D) heat conduction and (ii) the wall, to which the fins are attached, is included in the analysis. The problem is modeled as a 2D channel whose upper surface is flat and isothermal, while the lower surface has a periodic array of rectangular extensions/fins which are subjected to heat convection. The Biot number $(\mathrm{Bi}=\mathrm{h} \mathrm{t} / \mathrm{k})$ characterizing the heat transfer process is defined with respect to the thickness of the fins $(\mathrm{t})$. Numerical results suggest that the fins would enhance the heat transfer rate only if the Biot number is less than a critical value which is independent of the thickness of the wall, the length of the fins, and the period; the critical Biot number is approximately equal to 1.64. The optimum fins are infinitely thin and long, and densely packed, i.e., hairlike.
\end{abstract}

Original language

English

Article number

024504

Journal

$\underline{\text { Journal of Heat Transfer }}$

Volume

138

Issue number

2

Published - Feb 12016

Fyrillas, M. M., \& Leontiou, T. (2016). Critical Biot Number of a Periodic Array of Rectangular Fins. Journal of Heat Transfer, 138(2), [024504]. DOI: 10.1115/1.4031640 